\title{
Awe, Wonderment and the Ominous: The crossroad of art, science, technology and the spiritual
}

\author{
Blair Zaye \\ 7/7 Fountayne Rd, N15 4QL, \\ London, UK \\ exhibit@blairzaye.com
}

\section{INTRODUCTION}

Throughout this paper I shall look at how awe, wonderment and the ominous (AWO) are induced, deduced and can be reintroduced with the aid of emerging digital technologies, to construct a crossroad between art, science, technology and the spiritual.

As a multidisciplinary artist working in painting, drawing, video, performance and installation, I investigate the boundaries between: technology, consciousness, the esoteric, spirituality, the transcendental and the nature of realities. Exploring the links and differences between the tangible vs. the intangible, the duality or perhaps dichotomy of the taught concepts of the transcendental versus the genuine experience of it. This has led me to the focal point of AWO.

\section{AWO}

AWO (whether a heart melting sunset, the unfathomable Giza pyramids, the luminous cityscape of Shanghai, a mystical experience of a luscious natural landscape or peering into the soul of a lover via their optical windows) is a felt ontological, psychological and physiological response through direct experience of inexplicable and indescribable amazement, pertaining to a place, person or situation. The self proclaimed 'wonder junkie' Jason Silva puts it best while referencing Keltner \& Haidt (2003) in one of his highly popular YouTube series 'Shots Of Awe' when he describes awe as 'An experience of such perceptual vastness you literally have to reconfigure your mental models of the world to assimilate it' (Silva 2013). Moreover, in 'The development of the Awe Experience Scale' we see 'perceived time dilation, self-diminishment, connectedness and involuntary physical sensations', (Yaden, Barry Kaufman, Hyde, Chirico, Gaggioli, Zhang \& Keltner 2018), added to the mix.

\section{INDUCE}

My early attempts to relay ideas of the esoteric, the transcendental and awe via a subjective point of view were considered dogmatic and didactic, creating a barrier between the experience and the viewer. As such, I have moved away from the (re)presentation of knowledge, reconfiguring my approach toward the felt experience of AWO, successfully setting up immersive environments and stimulation to embody these ideas through direct, lived, transcendental experience for the viewer to reflect on. This new approach was embodied within my installation 'Imago Dei'.

Imago Dei; manifested as a rusty corrugated iron wall, symbolic of degradation. In the top a hole is cut out with a projected pulsing representing a kind of consciousness, or a portal to another dimension, as sub-frequency bass permeates through the viewer and is coupled with a soundscape of isochronic tones, which are used to gain altered states of consciousness (Lewis 2018). These elements create a liminal space for the viewer to walk into, get lost in and transcend.

This approach has been proven affective at creating AWO by conducting experience surveys over the course of 4 iterations of the installation. One viewer described the experience as 'epic and godly' and delivering an 'awe-inspiring' feeling. Another can be quoted as saying 'Imago Dei is an imagining of the core of the universe. By means of hypnotic visuals and reverberations that shake the surrounding matter, the experiencer is able to transcend reality and enter a new state of being.' 
And yet another 'I felt it was somewhat the end of time yet equally the birth of the universe... mirroring the vastness' (Zaye 2018-2019).

\section{DEDUCE}

Now that we have a descriptive account of AWO and how it can be achieved, we must look at how it can be recorded. AWO creates physiological and psychological responses as such it can now be quantified.

In the field of psychology the 'Awe Experience Scale' is a test to measure the psychological effects within the sphere of awe (Yaden \& Barry Kaufman, Hyde, Chirico, Gaggioli, Zhang \& Keltner 2018). Where as, physically, fluctuations such as; accelerated heartbeat and changes of the electrical activity of the brain occur; these can be recorded with the aid of technology via a heart rate monitor and an electroencephalogram (EEG) headset. Using renditions of the above Cirque Du Soleil, which is 'arguably the most successful live show at evoking feelings of "awe" (Morris 2018) has hired the likes of 'experiential research lab' Lab Of Misfits to measure the effects of awe on their audience. 'Creating the first ever neural metric for human experiences of awe and wonder' while providing a scientifically backed insight into awe (Lab Of Misfits 2018).

\section{REINTRODUCE}

Throughout time artists have always sought and conceived AWO. It is only now, with the integration of technologies in the artistic realm of new media, has the relationship between AWO and artist been actualised. For example, Marshmallow Laser Feast's 'We Live in an Ocean of Air', is a virtual reality experience, part of which captures physiology using a heart rate monitor to utilise your heartbeat so that you virtually see it within your body in VR, and a breath sensor to visualise your breath into interactive swirling particles. (Marshmallow Laser Feast 2018). Similarly, Fuse*'s multimedia performance 'DOKK' uses various forms of new media; sensors, projections and generative $\mathrm{Al}$, more specifically it captures the heart beat via a Bluetooth BLE sensor strapped to the performers chest, transmitting data wirelessly in real time, which is sequenced at both the beginning and end of the performance to effect the visuals, a reflection of the performers resting heart rate and rise due to physical exertion (Fuse* 2017).

Following on, with research and development over the coming months, my next proposed installation, 'Cymatics v Somatics', will step deeper into the world of AWO, mining physiological data of the audience in real-time, which is then fed back into the installation, interacting and changing multimedia variables such as intensity and frequency. The hope is that by making the installation responsive, it will make the viewer more immersed and in awe, to create a biofeedback loop, syncing a symbiotic relationship between person and environment.

In time this is to be pushed further by creating installations that are truly reactionary and interactive. Resulting in awe, wonderment and the ominous evolving from the subjective, into the intersubjective and in turn, the objective.

\section{REFERENCES}

Barry Kaufman, S. (2018) Can You Quantify Awe? https://scottbarrykaufman.com (retrieved 25 March 2019).

Cirque du Soleil (2018) Cirque du Soleil unlocks the mysteries of AWE.

https://www.cirquedusoleil.com (retrieved 25 March 2019).

fuse $^{*}$ (2017) DOKK. https://www.fuseworks.it (retrieved 25 March 2019).

Keltner, D. and Haidt, J. (2003) Approaching awe, a moral, spiritual, and aesthetic emotion, Cognition \& Emotion, 17, p.297-314.

Kotler, S. and Wheal, J. (2018) Stealing Fire. Dey Street Books.

Lab Of Misfits (2018) The Experiential Experiments. http://www.labofmisfits.com/ (retrieved 25 March 2019).

Lewis, J. (2018). Isochronic Tones, Mind Amend. https://www.mindamend.com (retrieved 25 March 2019).

Marshmallow Laser Feast (2018). We Live In An Ocean Of Air. https://www.marshmallowlaserfeast.com (retrieved 25 March 2019).

Morris, A. (2018) Cirque Du Soleil Hires A Neuroscientist To Unlock The Mystery Of 'Awe'. https://www.forbes.com/

(retrieved 25 March 2019).

Shots of Awe with Jason Silva (2018) Awe. https://youtu.be/8QyVZrV3d3o (retrieved 25 March 2019).

Yaden, D. B., Barry Kaufman, S., Hyde, E., Chirico, A., Gaggioli, A., Wei Zhang J. and Keltner, D. (2018) The development of the Awe Experience Scale (AWE-S), The Journal of Positive Psychology.

Zaye, B. (2018) Cymatics v Somatics. https://youtu.be/G9 fzdMTB5Y (retrieved 25 March 2019).

Zaye, B. (2018) Imago Dei Installation. https://youtu.be/Zbdtm6dg4ls (retrieved 25 March 2019).

Zaye, B. (2018) Pariah Performance. https://youtu.be/KCqqT4uSEWI (retrieved 25 March 2019).

Zaye, B. (2018-2019) Experience Survey - Imago Dei. 